\title{
Effects of Community-Dwelling Older Adults' Demographics and Social, Mental, and Physical Functions on Depressive Disorder
}

\author{
Donguin LeE ${ }^{1)}$, Taesung $\left.\mathrm{Ko}^{2}\right)^{*}$, Shangwhan Han ${ }^{1)}$ \\ 1) Department of Physical Therapy, Gwangju Health College \\ 2) Department of Physical Therapy, Daewon University College: 316 Daehak-ro, Jecheon Chungbuk \\ 390-702, South Korea.TEL +82 43-649-3156
}

\begin{abstract}
Purpose] To identify the relationship between depressive disorder prevalence and cognitive and physical functions of community-dwelling older adults. [Methods] The study subjects were 95 adults over the age of 65 residing in J City. Social and demographic characteristics, cognition, balance, walking, and instrumental activities of daily living (IADLs) were evaluated, along with depressive disorder symptoms, and analyzed with logistic regression. [Results] Depressive disorder among senior citizens was related to the death of a spouse, disease status, ability to walk $10 \mathrm{~m}$, and IADLs. [Conclusion] Interventions that employ social and physical therapeutic approaches to enhance locomotion and activities of daily living (ADLs) through the promotion of psycholoical stability might be effective for senior citizens with depressive disorders.

Key words: Activities of daily living, Depressive disorder, Older adults
\end{abstract}

(This article was submitted Oct. 31, 2012, and was accepted Dec. 4, 2012)

\section{INTRODUCTION}

Generally, depression, one of many psychiatric disorders, has various causes, including sociological, family and mental problems, and may result in the deterioration of physical functions ${ }^{1)}$. Depressive disorders among the elderly are related to physical disease, retirement, poverty, social isolation, death of a spouse, and alienation from family. Such disorders tend to progress rapidly and have serious consequences, including psychosocial damage, physical disease, economic loss, and suicide ${ }^{2)}$. Because cognitive dysfunction is highly correlated with depressive disorders among the elderly, it should be carefully observed and stud$i^{3}{ }^{3)}$. Physical attributes, such as balance, can also help us to understand depressive disorders in old age. Among seniors who experience balance problems, such as vertigo and dizziness, prevalence of injury from a fall, as well as increased depressive disorders and fear, can lead to a decline in quality of life ${ }^{4)}$. A study of 312 community-dwelling older adults with mild depressive symptoms and no dementia found significant relationships between depressive symptoms and disease, mobility problems, and walking speed, suggesting that uncomfortable locomotion might be a factor influencing depressive disorders ${ }^{5}$.

Physical function can be evaluated through activities of daily living (ADLs) and instrumental activities of daily living (IADLs). IADLs are used to evaluate higher order functional movements and the execution of personal tasks necessary for independent living ${ }^{6}$. One study reported

*To whom correspondence should be addressed.

E-mail: intkts@korea.com that ADL limitations could increase the prevalence of depressive disorders, and that other diseases, e.g. arthritis, can limit IADLs resulting in depressive disorders ${ }^{7}$. Both stable disability status and transitions in disability status are significantly related to changes in depressive symptoms. Depression (depressive disorder) improves in a stable condition. Psychologically stable family relationships, social relationships, and economic stability also help to improve the functions of the body through improvement of depres$\operatorname{sion}^{8)}$.

Home-visit rehabilitation is effective at improving mental function and tendencies toward depression, as well as ADLs for frail older adults whohave been discharged from acute hospital stays ${ }^{9}$.

Recently, several studies have assessed social aspects related to depressive disorders, but few studies have examined how physical function relates to depressive disorders. The purpose of the present study was, therefore, to investigate the influence of social and demographic characteristics, cognition, balance, and walking on exercise treatments/rehabilitation for older adults with depressive disorders.

\section{SUBJECTS AND METHODS}

\section{Subjects}

Subjects were residents of J City over the age of 65 years, who were capable of independent gait, independent living, and communicating at a level where they could participate in a survey and understand the purpose of this study. Eleven individuals who did not answer the questions truthfully and 4 who were taking antidepressants were excluded from an original sample of 110 older adults. Thus, a final sample of 
95 older adults participated in this study.

\section{Methods}

This was a cross-sectional study. We used the Beck Depression Inventory (BDI), which included items assessing cognition, emotion, motivation, and physical symptoms. This measure consists of 21 items and each item is scored on a scale ranging from mild (0) to severe $(3)^{10)}$. We categorized participants who scored over 13 as depressed ${ }^{11)}$. The Revised Hasegawa Dementia Scale (HDS-R) was used to assess cognitive ability. The questions assess domains such as time, orientation, and place, with higher scores signaling fewer errors committed. The HDS-R does not require any reading or writing, so it is less influenced by education level and age, which is also the case with the Mini Mental State Examination (MMSE). The HDS-R also includes fewer movement tasks, such as execution ability and space organization. Therefore, the HDS-R can be used with older adults with vision or motor problems ${ }^{12}$. The FICSIT-4 (Frailty and Injuries Cooperative Studies of Intervention Techniques) was used to examine balance. This assessment requires the participants to adopt 4 positions: the parallel, semi-tandem, tandem, and one-leg standing stances. These positions were performed with the eyes open and closed. The score for each item ranges from 0 to 4 points, with the maximum total score obtainable being 28 points $^{13}$ ) Each position was adopted for a maximum of $10 \mathrm{~s}$. During the assessment, the examiner took precautions to ensure that participants would not fall. A 10-m walking test was used to assess participants' walking ability; this measure has been reported to have high inter-rater reliability $(r=0.98)$ and high intra-rater reliability $(r=0.97)^{14}$. Subjects were asked to walk over a $14-\mathrm{m}$ course at maximum speed, and the time taken to walk the $10 \mathrm{~m}$, excluding $2 \mathrm{~m}$ at the start and $2 \mathrm{~m}$ after the finish line, to control for acceleration and deceleration, was measured in seconds. For the ADL assessment, the Korean version of the Instrumental Activities of Daily Living Scale (K-IADL) was used ${ }^{15)}$.

SPSS 18.0 was used for statistical analysis, and means and standard deviations were calculated for all our measures. Pearson's $\chi^{2}$ and Fisher's exact tests were used to assess differences in depressive disorder prevalence, and the independent $t$-test was used to assess differences in prevalence according to cognitive and physical characteristics. Finally, logistic regression analysis was conducted with statistically significant variables. Statistical analyses were conducted with a $95 \%$ confidence level. The significance level $(\alpha)$ was chosen as 0.05 .

\section{RESULTS}

Marriage and disease status significantly correlated with depressive disorders $(\mathrm{p}<0.05)$ (Table 1). Scores on the FICSIT-4 and HDS-R did not significantly differ in terms of depressive disorders. However, our results suggest a statistically significant influence of the $10-\mathrm{m}$ walking speed and K-IADLs assessment on depressive disorders $(\mathrm{p}<0.05)$ (Table 2). In our logistic regression analysis, being divorced $(\mathrm{OR}=0.192,95 \% \mathrm{CI}=0.053-0.695)$ and disease state $(\mathrm{OR}$
Table 1. Comparison of sociodemographic characteristics between the groups

\begin{tabular}{|c|c|c|}
\hline Varables & $\begin{array}{l}\text { Depressive } \\
\text { group }(n=36)\end{array}$ & $\begin{array}{c}\text { Normal } \\
\text { group }(n=59)\end{array}$ \\
\hline \multicolumn{3}{|l|}{ Gender } \\
\hline Male & $12(33.3) *$ & $47(79.7)$ \\
\hline Female & $24(66.7)$ & $12(20.3)$ \\
\hline \multicolumn{3}{|l|}{ Age (yr) } \\
\hline $65-70$ & $3(8.3)$ & $5(8.5)$ \\
\hline $71-75$ & $12(33.3)$ & $12(20.3)$ \\
\hline $76-80$ & $15(41.7)$ & $21(35.6)$ \\
\hline $81-85$ & $2(5.6)$ & $15(25.4)$ \\
\hline$\geq 86$ & $4(11.1)$ & $6(10.2)$ \\
\hline \multicolumn{3}{|l|}{ Place } \\
\hline Senior community center & $21(58.3)$ & $37(62.7)$ \\
\hline Senior welfare center & $15(41.7)$ & $22(37.3)$ \\
\hline \multicolumn{3}{|l|}{ Marital status $\dagger$} \\
\hline Single & $1(2.8)$ & $2(3.4)$ \\
\hline Married & $5(13.9)$ & $17(28.8)$ \\
\hline Divorced & $1(2.8)$ & $1(1.7)$ \\
\hline Widowed & $29(80.6)$ & $39(66.1)$ \\
\hline \multicolumn{3}{|l|}{ Education level } \\
\hline None & $13(36.1)$ & $24(40.7)$ \\
\hline Elementary school & $15(41.7)$ & $25(42.4)$ \\
\hline Middle school & $4(11.1)$ & $9(15.3)$ \\
\hline Higher school & $4(11.1)$ & $1(1.7)$ \\
\hline \multicolumn{3}{|l|}{ Disease $\dagger$} \\
\hline Yes & $34(94.4)$ & $45(76.3)$ \\
\hline No & $2(5.6)$ & $14(23.7)$ \\
\hline
\end{tabular}

*: number (percent)

$\dagger$ : Significant difference between groups $(\mathrm{p}<0.05)$

Table 2. Comparison of cognitive, physical characteristics between the groups

\begin{tabular}{lcc}
\hline Variables & $\begin{array}{c}\text { Depressive } \\
\text { Group }(\mathrm{n}=36)\end{array}$ & $\begin{array}{c}\text { Normal } \\
\text { Group }(\mathrm{n}=59)\end{array}$ \\
\hline HDS-R (point) & $21.0(4.6)^{*}$ & $21.9(4.8)$ \\
10m walking speed $(\mathrm{s}) \dagger$ & $25.5(10.4)$ & $21.7(5.5)$ \\
FICSIT-4 (point) & $19.7(4.5)$ & $20.8(5.4)$ \\
K-IADL (point) $\dagger$ & $14.3(2.7)$ & $13.3(2.2)$ \\
\hline
\end{tabular}

*: Mean (standard deviation)

$\dagger$ : Significant difference between groups $(\mathrm{p}<0.05)$

HDS-R: Revised Hasegawa Dementia Scale; FICSIT-4: Frailty and Injuries Cooperative Studies of Intervention Techniques; KIADL: Korean version of the Instrumental Activities of Daily Living Scale

$=0.062,95 \% \mathrm{CI}=0.003-0.451)$ significantly predicted depressive disorders. With regard to physical aspects, $10-\mathrm{m}$ walking speed $(\mathrm{OR}=0.906,95 \% \mathrm{CI}=0.846-0.971)$ and K-IADLs (OR $=0.597,95 \% \mathrm{CI}=0.443-0.803)$ predicted depressive disorders in our subjects (Table 3 ). 
Table 3. Muliple logistic regression analysis of depressive symptoms by related variables

\begin{tabular}{lcc}
\hline \multicolumn{1}{c}{ Variables } & OR & $95 \%$ CI \\
\hline Marital status & & \\
$\quad$ Married & 1.000 & \\
Divorced & 0.192 & $0.053-0.695$ \\
Single & 0.280 & $0.017-4.525$ \\
$\quad$ Widowed & 0.184 & $0.007-4.700$ \\
Disease & & \\
No & 1.000 & \\
$\quad$ Yes & 0.062 & $0.008-0.451$ \\
10m walking speed & 0.906 & $0.846-0.971$ \\
K-IADL & 0.597 & $0.443-0.803$ \\
\hline
\end{tabular}

OR: odds ratio; CI: confidence interval

K-IADL: Korean version of the Instrumental Activities of Daily Living Scale

\section{DISCUSSION}

In this study, gender, age, survey area, and education level did not predict the depressive disorders of our subjects. On the other hand, marriage and disease status were found to predict depressive disorder prevalence. Ladin ${ }^{16)}$ argues that depressive disorder prevalence is higher among people who did not graduate from high school, and Weissman et al. ${ }^{17)}$ found that its prevalence is higher in women than in men, but that age is not a predictor of depressive disorder. Thus, our results do not fully corroborate past findings. This might be due to the fact that these previous studies assessed bipolar surgery patients and sampled a larger group of participants. However, some previous studies had results similar to ours, finding that marriage ${ }^{18)}$ and disease status ${ }^{2)}$ predict depressive disorders. Thus, divorce, pain from disease, and discomfort in one's daily life appear to be influential factors in the development of depressive disorders. Additionally, family life post-marriage is closely related to depressive disorders, as depressive disorder prevalence is higher among elderly adults who are divorced than among those with a deceased spouse.

Cognitive decline, as measured by the HDS-R, did not predict depressive disorders in the current study. However, depressive disorders could lead to cognitive difficulties and may predict cognitive dysfunction ${ }^{19}$. Some previous studies have shown a correlation between cognitive dysfunction or depressive symptoms and decline in physical functioning $^{20)}$. However, other studies found no relationship between cognitive dysfunction and depressive disorders. Thus, an investigation of additional factors that could predict physical decline in older adults is warranted ${ }^{21)}$. The relationship between depressive disorders and cognition is influenced by many variables, which makes an assessment of social and physical factors necessary. Although balance did not correlate significantly with depressive disorder prevalence in this study, $10-\mathrm{m}$ walking speed and IADLs differed significantly with depressive disorder status. These results differ from those of previous studies in that recollection treatment for a Chinese elderly sample contributed to improved depressive disorders and balance ${ }^{22}$, while another revealed a correlation between injuries from falls (caused by imbalance due to stroke) and depressive disorders ${ }^{23}$. The difference in results could be due to the sense of balance in our sample being better than that of people who have suffered a stroke. However, decline in walking speed could result in stress, which may trigger a depressive disorder. Decline in walking speed is related to depressive disorders, and walking speed is a powerful predictor of major depressive dis$\operatorname{order}^{24)}$. Depressive disorders among community-dwelling older adults are highly correlated with IADLs ${ }^{25}$; thus, the degree of instrumental impairment can greatly affect depressive disorder.

Therefore, practical tasks during physical therapy that can enhance ADLs are needed to decrease depressive disorder prevalence among older adults. In addition, analysis of the correlation between the degree of depressive disorders and physical factors should be investigated to rehabilitate older adults who are suffering from depressive disorders.

\section{REFERENCES}

1) Hwang SH, Rhee MK, Kang RH, et al.: Development and validation of a screening scale for depression in Korea: the lee and rhee depression scale. Psychiatry Investig, 2012, 9: 36-44. [Medline] [CrossRef]

2) Tsuang MT, Woolson RF, Fleming JA: Premature deaths in schizophrenia and affective disorders. An analysis of survival curves and variables affecting the shortened survival. Arch Gen Psychiatry, 1980, 37: 979-983. [Medline] [CrossRef]

3) Teri L, Wagner A: Alzheimer's disease and depression. J Consult Clin Psychol, 1992, 60: 379-391. [Medline] [CrossRef]

4) Gallagher B, Corbett E, Freeman L, et al.: A fall prevention program for the home environment. Home Care Provid, 2001, 6: 157-163. [Medline] [CrossRef]

5) Albert SM, Bear-Lehman J, Burkhardt A: Mild depressive symptoms, selfreported disability, and slowing across multiple functional domains. Int Psychogeriatr, 2012, 24: 253-260. [Medline] [CrossRef]

6) Peel C, Sawyer B, Roth DL, et al.: Assessing mobility in older adults: the UAB study of aging life-space assessment. Phys Ther, 2005, 85: 10081119. [Medline]

7) An JY, Tak YR: Depressive symptoms and related risk factors in old and oldest-old elderly people with arthritis. J Korean Acad Nurs, 2009, 39: 72-83. [Medline] [CrossRef]

8) Yang Y, George LK: Functional disability, disability transitions, and depressive symptoms in late life. J Aging Health, 2005, 17: 263-292. [Medline] [CrossRef]

9) Kawagoe M, Kajiya S, Mizushima K, et al.: Effect of continuous homevisit rehabilitation on functioning of discharged frail elderly. J Phys Ther Sci, 2009, 21: 343-348. [CrossRef]

10) Beck AT, Ward CH, Mendelson M, et al.: An inventory for measuring depression. Arch Gen Psychiatry, 1961, 4: 561-571. [Medline] [CrossRef]

11) Lee YW, Park EJ, Kwon IH, et al.: Impact of psoriasis on quality of life: relationship between clinical response to therapy and change in health-related quality of life. Ann Dermatol, 2010, 22: 389-396. [Medline] [CrossRef]

12) Jeong JW, Kim KW, Lee DY, et al.: A normative study of the revised Hasegawa dementia scale: comparison of demographic influences between the revised Hasegawa dementia scale and the mini-mental status examination. Dement Geriatr Cogn Disord, 2007, 24: 288-293. [Medline] [CrossRef]

13) Buchner DM, Hornbrook MC, Kutner NG, et al.: Development of the common data base for the FICSIT trials. J Am Geriatr Soc, 1993, 41: 297-308. [Medline]

14) van Hedel HJ, Wirz M, Dietz V: Assessing walking ability in subjects with spinal cord injury: validity and reliability of 3 walking test. Arch Phys Med Rehabil, 2005, 86: 190-196. [Medline] [CrossRef]

15) Na HR, Lee SH, Lee JS: Korean version of the Baylor profound mental status examination: a brief staging measure for patients with severe Alzheimer's disease. Dement Geriatr Cogn Disord, 2009, 27: 69-75. [Medline] [CrossRef]

16) Ladin K: Risk of late-life depression across 10 European Union countries: 
deconstructing the education effect. J Aging Health, 2008, 20: 653-670. [Medline] [CrossRef]

17) Weissman MM, Bland R, Jocye PR, et al.: Sex differences in rates of depression: cross-national perspectives. J Affect Disord, 1993, 29: 77-84. [Medline] [CrossRef]

18) Rotermann M: Marital breakdown and subsequent depression. Health Rep, 2007, 18: 33-44. [Medline]

19) Gallo JJ, Rabin PV: Depression without sadness: alternative presentations of depression in late life. Am Fam Physician, 1999, 60: 820-826. [Medline]

20) Cronin-Stubbs D, de Leon CF, Beckett LA, et al.: six-year effect of depressive symptoms on the course of physical disability in community-living older adults. Arch Intern Med, 2000, 160: 3074-3080. [Medline] [CrossRef]

21) Mehta KM, Yaffe K, Covinsky KE: Cognitive impairment, depressive symptoms, and functional decline in older people. J Am Geriatr Soc, 2002,
50: 1045-1050. [Medline] [CrossRef]

22) Zhou W, He G, Gao J, et al.: The effects of group reminiscence therapy on depression, self-esteem, and affect balance of Chinese communitydwelling elderly. Arch Gerontol Geriatr, 2012, 54: e440-447. [Medline] [CrossRef]

23) Takatori K, Shomoto K, Shimada T: Relationship between self-perceived postural limits and falls among hospitalized stroke patients. J Phys Ther Sci, 2009, 21: 29-35. [CrossRef]

24) Peeters F, Berkhof J, Rottenberg J, et al.: Ambulatory emotional reactivity to negative daily life events predicts remission from major depressive disorder. Behav Res Ther, 2010, 48: 754-760. [Medline] [CrossRef]

25) Nyunt MS, Lim ML, Yap KB, et al.: Changes in depressive symptoms and functional disability among community-dwelling depressive older adults. Int Psychogeriatr, 2012, 24: 1633-1641. [Medline] 